\title{
Intraindividual Differences in Motivation and Cognition in Students With and Without Learning Disabilities
}

\author{
Paul R. Pintrich, Eric M. Anderman, \\ and Cheryl Klobucar
}

The present study examines several cognitive and motivational variables that distinguish children with learning disabilities $(n=19)$ from children without learning disabilities $(n=20)$. The total sample included 30 males and 9 females and was composed of white, fifth-grade students from a middle-class community in the Midwest. Results showed that although the students with learning disabilities displayed lower levels of metacognitive knowledge and reading comprehension, they did not differ from the students without learning disabilities on self-efficacy, intrinsic orientation, or anxiety. In addition, they did not show any signs of learned helplessness, although they did tend to attribute success and failure to external causes more often than the students without learning disabilities. Using a cluster analysis that grouped individuals, we found that differences in the motivational and cognitive variables cut across a priori categories of children with and without learning disabilities. Three clusters were formed: one with high comprehension, motivation, and metacognition (mostly children without learning disabilities); one with low levels of comprehension and metacognition but high intrinsic motivation (all children with learning disabilities); and one with low intrinsic motivation but average comprehension, metacognition, and attributional style (approximately equal numbers of children with and without learning disabilities). Implications for diagnosis and intervention for students with learning disabilities are discussed.

D escriptive research on children with learning disabilities (LD) often does not integrate cognitive and motivational perspectives on learning, even though current views of student learning in the classroom context suggest that both motivation and cognition are important components of successful academic performance (Pintrich \& De Groot, 1990). McKinney (1989; McKinney \& Speece, 1986) suggested that the classification of students with learning disabilities into various subgroups provides a richer description of learning disabilities than do more typical correlational studies. Yet, previous research that has attempted to classify students into subtypes has emphasized cognitive and behavioral characteristics, without much consideration for the interactions among cognition, motivation, and behavior. The present study extends the previous work of McKinney (1989), Lipson and Wixson (1986), and Pintrich (1989) by examining intraindividual differences in patterns of motivation and cognition in students with and without learning disabilities.

Current views of student learning suggest that both motivation and cognition are important components of successful academic performance (Pintrich \& De Groot, 1990; Pintrich \& Schrauben, 1992). The integration of motivational and cognitive compo- nents provides a much more detailed model of student learning. The motivational literature has tended to focus on how motivational beliefs lead to choice and persistence without addressing what cognitive tools the learner may use to accomplish his or her goals, thus incorrectly depicting a "cognitively poor" learner. At the same time, cognitive models have focused on developing models of competence, not classroom performance, which tend to ignore issues of purposes, goals, and motivation, thus incorrectly depicting a "motivationally inert" learner (Pintrich \& Garcia, 1991).

The literature on at-risk students and students with LD has tended to follow this separation of research on the motivational and cognitive components of academic performance. However, recent research is beginning to address both motivation and cognition in atrisk children (e.g., Borkowski, Carr, Rellinger, \& Pressley, 1990; Borkowski, Estrada, Milstead, \& Hale, 1989; Carr, Borkowski, \& Maxwell, 1991; Paris \& Oka, 1986a), as well as in other students (see review by Pintrich \& Schrauben, 1992). One purpose of this article is to continue in this tradition by examining the relations between motivation and cognition in two groups of elementary students, one group formally identified as having learning disabilities and receiving special educa- 
tion instruction (in a resource room but mainstreamed) by the school district, and the other group consisting of students without learning disabilities in a traditional classroom setting.

The conceptual model for motivation follows from our work on the expectancy components (self-efficacy and attributions), value components (intrinsic goal orientation), and affective components (anxiety) of student motivation (Pintrich, 1989; Pintrich \& De Groot, 1990; Pintrich \& Garcia, 1991; Pintrich \& Schrauben, 1992). There has been a great deal of research on the expectancy components of students' self-efficacy (e.g., Schunk, 1989) and attributional beliefs (e.g., Weiner, 1986). Generally, the research suggests that students with higher levels of selfefficacy will persist longer, be more likely to use cognitive strategies, and perform better than other students (Pintrich \& Schrauben, 1992). This general finding also has been shown in the special education literature (Chapman, 1988). The long history of research on students' attributional patterns suggests that attributing failure to internal causes, especially ability and not effort, can result in a "learned helplessness" style that is detrimental to future expectancies and behavior (Fincham \& Cain, 1986). In the literature on children with LD, this concept of attributional style is quite popular (Canino, 1981; Licht, 1983; Torgesen, 1982), although results have been mixed. Many studies have shown that students with LD do tend to attribute their failure to lack of ability (e.g., Butkowsky \& Willows, 1980; Kistner, Osborne, \& LeVerrier, 1988; Pearl, 1982); some studies have not found this pattern (e.g., Tollefson et al., 1982). In the present study, we expected that the sample of students with LD would have lower self-efficacy in reading and be more likely to attribute failure to ability than would the students without LD.

In terms of the value component of intrinsic goal orientation, there is a growing body of literature that shows that having a general learning or mas- tery goal (an intrinsic goal orientation) results in more cognitive engagement, including the use of "deeper" learning strategies and metacognitive and self-regulatory strategies (Graham \& Golen, 1991; Pintrich \& De Groot, 1990; Pintrich \& Schrauben, 1992). This construct has not been applied to the population of students with LD as often as the attributional- and learnedhelplessness-style constructs. However, Deci and Chandler (1986) suggested that intrinsic motivation variables may be central to learning disabilities. Ellis (1986) found that students with LD were not as intrinsically motivated as students without LD. Accordingly, it was expected that students with LD who had experienced a fair amount of failure in school and were receiving special education would be less intrinsically motivated than students without LD.

Finally, Dweck \& Leggett (1988) also suggested that students' orientation to performance goals (a focus on competition and grades) can lead to a pattern of motivational and cognitive beliefs that includes low self-efficacy, the learned-helplessness pattern of attributions, and increased anxiety. Anxiety also has been negatively related to cognitive performance (e.g., McKeachie, 1984; Tobias, 1985). Accordingly, we expected that the students with LD would show higher levels of anxiety than the students without LD.

Besides the differences in motivational beliefs for different groups of students, we were interested in how those beliefs were related to the cognitive and metacognitive components of learning. Metacognition is an important aspect of academic performance. There are two aspects of metacognition: knowledge and awareness of cognition, and control of cognition (Brown, Bransford, Ferrara, \& Campione, 1983). In this study, we focused on students' metacognitive knowledge of reading strategies. There is a great deal of research on students' metacognitive knowledge and its relation to performance that shows that students who have more strategic and conditional knowledge about memory, reading, or learning tend to do better on different academic and performance tasks (Paris \& Oka, 1986b; Paris \& Winograd, 1990; Schneider \& Pressley, 1989). This also applies to students with LD, who may not have acquired as much metacognitive knowledge as other students (Borkowski et al., 1989; Johnston \& Winograd, 1985; Wong, $1986,1987)$. At the same time, a number of researchers have suggested that metacognitive knowledge should be positively related to students' motivational beliefs regarding their efficacy, goal orientation, and attributions for performance (e.g., Borkowski et al., 1990; Pintrich, 1989).

In summary, the two questions we addressed in this study that relate to comparisons between students with and without learning disabilities in terms of their motivation and cognition were as follows:

- What are the differences in motivational beliefs (intrinsic goal orientation, self-efficacy, anxiety, and attributions) and metacognitive knowledge between students with and without LD?

- What are the relations between these motivational beliefs and metacognitive knowledge, as well as their relation to reading comprehension in general, and within groups specifically? Do the relations change as a function of group membership?

A second purpose of the article was to go beyond a comparison of the two groups of students and examine intraindividual differences in the pattern of relations between motivation and cognition. Pintrich (1989) found that different intraindividual patterns of motivation and cognition in college students can lead to the same achievement outcomes. Some students achieved through the use of cognitive and self-regulatory strategies, although they were rather low in intrinsic goal orientation or self-efficacy. Others were more motivated in terms of high- 
er self-efficacy beliefs and intrinsic goal orientation, although somewhat low in their use of cognitive strategies. This focus on the multivariate nature of intraindividual differences in motivation and cognition within similar achievement contexts is in line with recent models of individual-environment interaction (Scarr, 1992). Following this logic, there may be different intraindividual patterns of motivation and cognition that cut across the boundaries of a priori groups of students with and without LD. In addition, different patterns of motivation and cognition may be found within the group of students with LD, that is, different "types" of students with LD, depending on the context and the individual characteristics the student brings to that context (Lipson \& Wixson, 1986). This hypothesis is in line with the work of McKinney (1989), who found that different subgroups of students with LD can be formed and externally validated, using measures of classroom behavior, attention, and dependence. Accordingly, our third specific question for this article was the following:

- Are there intraindividual differences in the relations among motivation and cognitive variables that cut across a priori groups of children with and without LD?

\section{Method}

\section{Subjects}

The 39 subjects were all fifth-grade white students from two elementary schools in a middle-class school district near a large midwestern city. Of these 39 students, 19 (all males) were certified as having learning disabilities by the school system. The criteria used by the district to certify a student as having a learning disability required an IQ score in the normal range but an achievement score at least two grade levels below the expected level. In this district, all 19 students with LD were tested with the Wechsler Intelligence Scale for Children-Revised (WISC-R)
(Wechsler, 1974) (mean IQ for this sample $=98.4, S D=11.2$ ) and the Woodcock-Johnson achievement test (Woodcock \& Johnson, 1977). On the achievement test, all 19 students were shown to be reading at least two grade levels lower than their expected fifthgrade level, and all were mainstreamed but spent 1 to 2 hours a day in a resource room. (Originally, there were 20 students with LD, but 1 student did not complete all the tasks and was dropped from the study.)

The other 20 children (males $=11$, females $=9$ ) were students from traditional fifth-grade classrooms with no achievement problems; they constituted a random sample of those who had received parental permission to participate. To determine the approximate reading level of the students without $\mathrm{LD}$, we obtained scores from the Comprehensive Test of Basic Skills (CTBS) (1981), a district-administered group achievement test. The mean percentage score for 18 of these students was 62.1 , reflecting a normal range of achievement ( 2 of the students were new to the school district and consequently did not have scores). The students with LD did not take the group-administered CTBS because they are tested individually by the special education department to determine eligibility for services.

\section{Measures}

Two self-report questionnaires were used. A modified version of the Motivated Strategies for Learning Questionnaire (MSLQ) (Pintrich \& De Groot, 1990) included items on motivation and attributions for reading success and failure. All items on the MSLQ were rated on a 7-point Likert scale and asked specifically about reading. The scales for the motivation constructs were formed by taking the mean of several items, following Pintrich and De Groot. Three motivational scales were created: Intrinsic Orientation (alpha $=.87$ for this sample) reflected students' responses to eight items regarding their focus on learning and mastery, as well as their interest in and liking of reading (e.g., "Even when I do poorly in reading, I try to learn from my mistakes"). Selfefficacy (alpha $=.87$ ) was created from 10 items regarding students' beliefs about their confidence in accomplishing various reading tasks, such as understanding ideas, getting a good grade, and learning the material (e.g., "I'm certain that I can understand what I read"). The Anxiety scale (alpha $=.80$ ) was created from four questions about students' worry and concern over taking reading tests (e.g., "I worry a great deal about reading tests"). Previous use of the MSLQ (see Pintrich \& De Groot, 1990; Pintrich, Smith, Garcia, \& McKeachie, 1993) has shown similarly high reliability coefficients for internal consistency. In addition, these previous studies have shown moderate correlations (.30 to $.40)$ of the scales with academic performance measures, such as course grades, test scores, and seatwork, demonstrating reasonable predictive validity of the MSLQ.

The attributional measures asked students about their reactions to succeeding and failing at two general reading tasks: understanding what they read, and getting a good grade in reading. The students rated six attributions (ability, effort, task difficulty, luck, paying attention, and getting help) for each of those two tasks for both success and failure experiences, generating a total of 24 attributional items. These items were analyzed separately for general attributional patterns. In addition, six scales were created to reflect the three general attributional dimensions (Weiner, 1986) of locus (internal-external), stability (unstable-stable), and controllability (controllable-uncontrollable) for both success and failure situations. The internality scale was created by subtracting the ratings for external causes (luck, task difficulty, and assistance) from the ratings for internal causes (ability, effort, and attention), generating a scale that could range from 19 (very internal) to -19 (very external). 
The instability scale was created by subtracting the ratings for stable causes (ability, task difficulty) from the unstable causes (effort, luck, attention, and assistance), generating a scale that could range from 26 (very unstable) to -26 (very stable). The controllability scale was created by subtracting the uncontrollable causes (ability, luck, task difficulty) from the controllable causes (effort, attention, assistance), generating a scale that could range from 19 (very controllable) to -19 (very uncontrollable).

The Index of Reading Awareness (IRA) (Jacobs \& Paris, 1987) is a measure of students' knowledge of metacognitive strategies for reading, particularly comprehension strategies. The instrument consists of 20 multiple choice items, where one response is circled for each item. Each item is worth 0 to 2 points, with higher scores indicating greater metacognitive knowledge. A sample item was, "Why do you go back and read things over again?: (a) Because it is good practice [1 point], (b) Because you didn't understand it [2 points], or (c) Because you forgot some words [0 points]." Scores could range from 0 to 40 points. Jacobs and Paris reported that scores taken twice over an 8-month period were correlated moderately highly $(r=.55)$, demonstrating reasonable test-retest reliability. In addition, the IRA seems to provide a valid measure of metacognitive knowledge by distinguishing between good and poor readers and between students who had had a special treatment to increase metacognitive knowledge and those who did not have the instruction (Jacobs \& Paris, 1987).

Reading performance was measured by two comprehension tasks (Paris, Cross, \& Lipson, 1984). First, the students read a short story and responded to five multiple choice items about the story; they were not allowed to look back after reading the story. Scores on this task could range from 0 to 5 . A cloze task was then administered in which the subject read a story that had 10 missing words; the subject had to choose from a group of 4 possible choices to complete the sentence. Scores could range from 0 to 10 . Both reading tasks were at a fifth-grade level. They were used to provide standard measures of reading comprehension for both groups of students included in the study. Given that the school district had used a number of different assessment instruments to certify students with $L D$, the administration of these two standard measures provided us with comparability between the two groups in order to verify the a priori definition of the groups. In addition, the two comprehension measures provided more behavioral measures to complement the selfreport measures of motivation and cognition.

\section{Procedure}

Students responded to the questionnaires and the reading tasks in an individual session with a researcher.
After several practice items to make them familiar with the Likert scale, they responsed to the MSLQ by completing the rating scales as a researcher read the statements aloud to them. Second, the researcher read the Index of Reading Awareness items and the students selected one of the three choices for each item. The students then completed the reading comprehension and cloze tasks silently by themselves. The procedure took about 40 minutes.

\section{Results}

The first research question concerned differences in the mean levels of the variables between groups. Table 1 presents summary statistics and the mean differences between the groups on the motivational, metacognition, and comprehension measures. The results of a multivariate analysis of variance (MANOVA) for these six out-
TABLE 1

Group Differences for Motivation, Metacognition, and Comprehension Variables

\begin{tabular}{lccc}
\hline Variable & $\begin{array}{c}\text { Overall } \\
(\boldsymbol{n}=39)\end{array}$ & $\begin{array}{c}\text { Without LD } \\
(\boldsymbol{n}=\mathbf{2 0})\end{array}$ & $\begin{array}{c}\text { With LD } \\
(\boldsymbol{n}=\mathbf{1 9})\end{array}$ \\
\hline Anxiety & & & \\
$M$ & 3.29 & 3.33 & 3.26 \\
$S D$ & 1.91 & 2.08 & 1.76 \\
Intrinsic orientation & & & \\
$M$ & 5.60 & 5.54 & 5.66 \\
$S D$ & 1.24 & 1.03 & 1.45 \\
Self-efficacy & & & \\
$M$ & 5.55 & 5.71 & 5.37 \\
$S D$ & 1.12 & 1.00 & 1.24 \\
Metacognition & & & \\
$M$ & 28.23 & 30.40 & $25.95^{*}$ \\
$S D$ & 4.86 & 2.72 & 5.60 \\
Comprehension & & & \\
$M$ & 3.95 & 4.55 & $3.31^{*}$ \\
$S D$ & 1.32 & 0.60 & 1.56 \\
Cloze comprehension & & & \\
$M$ & 6.08 & 7.65 & $4.42^{* *}$ \\
$S D$ & 2.64 & 2.37 & 1.77 \\
\hline
\end{tabular}

Note. $\mathrm{LD}=$ learning disabilities.

${ }^{*} p<.01 .{ }^{* *} p<.001$. 
comes was significant, $F(5,33)=38.63$, $p<.001$, which demonstrates that there were significant differences among the dependent variables by group. Independent post hoc $t$ tests were run to examine the difference for each variable. The subjects without $L D$ scored higher than the students with LD on the first reading comprehension task, $t(37)=3.28, p<.01$, and on the cloze task, $t(37)=4.80, p<.001$, thereby providing verification of the reading comprehension problems of the students with LD as suggested by the school district's original testing and certification procedures. As hypothesized, the students without LD also displayed a greater awareness of metacognitive strategies on the Index of Reading Awareness, $t(37)=3.18$, $p<.01$. Contrary to expectations, however, no significant differences were found between students with and without LD on intrinsic orientation, self-efficacy, or anxiety.

Table 2 displays the summary statistics for the attributional measures. The MANOVA for attributions for success differed by group, $F(6,32)=3.57, p<$ .008 . Independent post hoc $t$ tests showed that students with LD were more likely to believe that their reading success was due to their ability, $t(37)=2.29, p<.05$. No significant differences were found between the two groups in their effort attributions for success. However, the students with LD did attribute reading success to easier tasks, $t(37)=2.32, p<.05$, and attributed reading success to luck, $t(37)=2.23, p<.05$, more than did students without LD. The students

TABLE 2

Summary Statistics and Group Differences for Attributional Variables

\begin{tabular}{|c|c|c|c|c|c|c|c|}
\hline Variable & $\begin{array}{c}\text { Overall } \\
(n=39)\end{array}$ & $\begin{array}{l}\text { Without LD } \\
(n=20)\end{array}$ & $\begin{array}{l}\text { With LD } \\
(n=19)\end{array}$ & Variable & $\begin{array}{l}\text { Overall } \\
(n=39)\end{array}$ & $\begin{array}{l}\text { Without LD } \\
(n=20)\end{array}$ & $\begin{array}{l}\text { With LD } \\
(n=19)\end{array}$ \\
\hline Success & & & & Luck & & & \\
\hline Ability & & & & $M$ & 2.03 & 1.65 & $2.42^{\star}$ \\
\hline$M$ & 4.92 & 4.38 & $5.50^{*}$ & $S D$ & 1.07 & 0.91 & 1.11 \\
\hline$S D$ & 1.62 & 1.63 & 1.42 & Attention & & & \\
\hline Effort & & & & $M$ & 4.36 & 4.85 & 3.84 \\
\hline$M$ & 5.69 & 5.78 & 5.60 & $S D$ & 1.80 & 1.75 & 0.78 \\
\hline SD & 1.35 & 1.10 & 1.58 & Assistance & & & \\
\hline Task difficulty & & & & $M$ & 2.81 & 1.93 & $3.74^{\star \star \star *}$ \\
\hline$M$ & 3.74 & 3.13 & $4.39^{*}$ & SD & 1.76 & 1.13 & 1.86 \\
\hline$S D$ & 1.81 & 1.85 & 1.54 & & & & \\
\hline Luck & & & & $\begin{array}{r}\text { Internality } \\
\text { Success }\end{array}$ & & & \\
\hline$M$ & 2.81 & 2.15 & $3.50^{*}$ & $M$ & 7.13 & 8.78 & $5.40^{* * *}$ \\
\hline$S D$ & 1.99 & 1.85 & 1.95 & $S D$ & 4.09 & 3.24 & 4.25 \\
\hline Attention & & & & Failure & & & \\
\hline$M$ & 6.41 & 6.45 & 6.37 & $M$ & 1.35 & 3.13 & $-.53^{* *}$ \\
\hline$S D$ & 0.86 & 0.94 & 0.61 & $S D$ & 4.11 & 3.94 & 3.47 \\
\hline \multicolumn{8}{|l|}{ Assistance } \\
\hline$M$ & 3.35 & 2.55 & $4.18 * *$ & Instability & & & \\
\hline \multirow[t]{2}{*}{ SD } & 1.81 & 1.40 & 1.83 & Success & & & \\
\hline & & & & $\begin{array}{l}M \\
S D\end{array}$ & $\begin{array}{l}9.59 \\
2.75\end{array}$ & $\begin{array}{l}9.43 \\
3.11\end{array}$ & $\begin{array}{l}9.76 \\
2.39\end{array}$ \\
\hline Ability & & & & Failure & & & \\
\hline$M$ & 1.95 & 2.00 & 1.89 & $\begin{array}{l}\text { raliure } \\
M\end{array}$ & 7.12 & 6.28 & 8.00 \\
\hline$S D$ & 1.36 & 1.40 & 1.33 & $S D$ & 3.78 & 3.44 & 3.99 \\
\hline \multicolumn{8}{|l|}{ Effort } \\
\hline$M$ & 4.04 & 4.18 & 3.89 & Controllability & & & \\
\hline$S D$ & 1.79 & 1.72 & 1.90 & $\begin{array}{c}\text { Success } \\
M\end{array}$ & 3.97 & 5.13 & 2.76 \\
\hline Task difficulty & & & & $S D$ & 4.19 & 4.68 & 3.31 \\
\hline & 4.17 & 4.33 & 4.00 & & & & \\
\hline \multirow[t]{2}{*}{$S D$} & 1.36 & 1.39 & 1.35 & $\begin{array}{l}\text { Failure } \\
\qquad M\end{array}$ & 3.97 & 2.98 & 3.16 \\
\hline & & & & $\begin{array}{l}M \\
S D\end{array}$ & $\begin{array}{l}3.97 \\
3.38\end{array}$ & 3.33 & 3.53 \\
\hline
\end{tabular}

Note. $L D=$ learning disabilities.

$" p<.05 . " * p<.01 . " * p<.001$. 
with $\mathrm{LD}$ also attributed reading success to having received assistance, $t(37)=$ $3.13, p<.01$.

The MANOVA for failure attributions was significant, $F(5,32)=3.78$, $p<.006$, but the only significant differences between the two groups relative to reading failure were for luck, $t(37)=2.39, p<.05$, and lack of assistance, $t(37)=3.70, p<.001$, both being higher for the students with LD. Accordingly, for the single attributional measures, the students with LD did not show any signs of the learnedhelplessness pattern of attributing their failure to lack of ability.

At the same time, the analysis of the three general scales of internality, instability, and controllability showed that the students with LD were different from the nondisabled group only on their internality scores. However, in contrast to the learned-helplessness model, they were more external for failure situations $(M=-.53$ for internality score for failure) in comparison to students without LD $(M=3.13)$, $F(1,37)=9.38, p<.004$. In addition, they were more external for success situations, $F(1,37)=7.85, p<.008$ (see Table 2 for means). This suggests that in this sample, the students with LD were more external for both success and failure situations. A separate analysis of just the ability and effort attributions for success and failure also showed no evidence of the learnedhelplessness pattern for the students with LD.

The second research question concerned the relations among the variables by group. Table 3 presents the zero-order correlations between the reading performance tasks and the measures of motivation and metacognition for the overall sample, as well as for the two groups of students separately. In terms of the overall correlations, the two measures of reading comprehension were highly correlated $(r=.55)$. Scores on the IRA were related to the reading comprehension task $(r=.42)$ and the cloze task $(r=.34)$, reflecting the common finding that students with more metacognitive knowledge about reading perform better on comprehension tasks. There was a very strong relationship between the measure of intrinsic orientation and self-efficacy $(r=.80)$; students with a mastery orientation were also likely to feel self-efficacious. Negative relationships were found between anxiety and the two reading tasks; that is, students who reported worrying about their performance on reading tests did not do well on the two comprehension tasks. Intrinsic orientation was positively related to metacognitive knowledge, with students who had a mastery orientation to reading reporting more awareness of different reading strategies.

The global attributional scales also showed the expected positive relations with the other motivational and cognitive measures (see Table 4). Students who attributed their reading success to internal causes were less anxious, more mastery oriented, more selfefficacious, and more metacognitive, and they performed better. The other main attributional variable that had consistently significant relations with the other variables was attributing success to controllable factors. Students who attributed their reading success to controllable factors were likely to be less anxious and more metacognitive and to perform better (see Table 4). In addition, students who believed that their failure was due to unstable or uncontrollable causes were less mastery oriented and less efficacious.

Besides the overall correlations, a second part of the second research question concerned differences in correlations between the two groups of students. Table 3 also displays the correlations by group for the motivational, metacognitive, and comprehension measures. The use of a $z$ transformation to test for differences in correlations between groups revealed no statistical differences in the correlations between groups. Although there were some rather large differences in correlations (e.g., anxiety strongly negatively related to comprehension for the students with LD and only marginally related to comprehension for students without LD), these differences are not reliable, given the small $n$ and subsequent loss of statistical power.

The third research question concerned intraindividual differences in the pattern of the relations among the motivational, metacognitive, and comprehension measures. Following Pintrich (1989) and McKinney (1989), we performed a P-type cluster analysis that clustered individuals into groups that shared the same pattern of motivation, metacognition, and comprehension. The cluster analysis used correlations as the distance measure and used Ward's method to form clusters based on six measures-the three motivational measures (intrinsic orientation, self-efficacy, and anxiety), metacognitive awareness, and the two comprehension measures. The selection of the appropriate cluster solution was predicated on two criteria: parsimony and significant differences in the vectors of the scores by cluster group as tested in a MANOVA (Aldenderfer \& Blashfield, 1984). That is, we selected the smallest number of groups that still generated significant differences in at least some of the six variables that were entered in the cluster analysis. This procedure resulted in a three-group solution to the cluster analysis, with 15 students in Cluster 1 , 14 in Cluster 2, and 10 in Cluster 3.

Table 5 shows the mean differences in the six variables as a function of cluster group membership. As noted above, an overall MANOVA was significant, $F(12,64)=6.36, p<.01$, and was followed by individual ANOVAs and post hoc tests to determine the differences between the groups on the separate scales. The two variables that best distinguished between the three groups were metacognitive awareness, $F(2,36)=82.15, p<.0001$, and cloze comprehension, $F(2,36)=7.29, p<$ .002 . Post hoc tests showed that students in Cluster 1 were highest in metacognitive awareness and cloze performance, followed by students in Cluster 2; the lowest students in both 
TABLE 3

Zero-Order Correlations Among Motivation, Metacognition, and Comprehension Variables

\begin{tabular}{|c|c|c|c|c|c|c|}
\hline Variable & Anxiety & Intrinsic orientation & Self-efficacy & Metacognition & Comprehension & Cloze comprehension \\
\hline $\begin{array}{l}\text { Intrinsic orientation } \\
\text { Non-LD } \\
\text { LD }\end{array}$ & $\begin{array}{r}-.03 \\
-.26 \\
.18\end{array}$ & & & & & \\
\hline $\begin{array}{c}\text { Self-efficacy } \\
\text { Non-LD } \\
\text { LD }\end{array}$ & $\begin{array}{l}-.06 \\
-.10 \\
-.02\end{array}$ & $\begin{array}{l}.80^{\star * *} \\
.67^{\star * *} \\
.90^{\star * *}\end{array}$ & & & & \\
\hline $\begin{array}{l}\text { Comprehension } \\
\text { Non-LD } \\
\text { LD }\end{array}$ & $\begin{array}{l}-.33^{*} \\
-.13 \\
-.59^{* *}\end{array}$ & $\begin{array}{l}-.23 \\
-.23 \\
-.25\end{array}$ & $\begin{array}{l}-.08 \\
-.17 \\
-.18\end{array}$ & $\begin{array}{c}.42^{\star \star} \\
-.27 \\
.36\end{array}$ & & \\
\hline
\end{tabular}

Note. Non-LD $=$ without learning disabilities; $L D=$ with learning disabilities

$" p<.05 . " * p<.01 . " * p<.001$.

TABLE 4

Correlations Among Attributional Variables and Motivation, Metacognition, and Comprehension Variables

\begin{tabular}{|c|c|c|c|c|c|c|}
\hline Variable & Internal success & Internal failure & Unstable success & Unstable failure & Control success & Control failure \\
\hline Intrinsic orientation & $.26 * *$ & -.07 & -.16 & $-.39^{* *}$ & -.10 & $-.30^{*}$ \\
\hline Metacognition & $.27^{*}$ & .25 & .13 & -.06 & $.49^{* \star *}$ & .10 \\
\hline Comprehension & $.28^{*}$ & .09 & -.16 & -.12 & $.28^{*}$ & -.12 \\
\hline Cloze comprehension & $.47^{* * *}$ & $.28^{*}$ & -.14 & $-.29^{*}$ & $.35^{* *}$ & -.10 \\
\hline
\end{tabular}

$" p<.05 .{ }^{* * p}<.01 .{ }^{* *} p<.001$.

asures were those in Cluster 3. In addition, Cluster 1 students performed much better on the simple measure of comprehension in comparison to Cluster 3 students, $F(2,36)=4.24, p$ $<.02$. The only significant difference in the motivation measures was for intrinsic goal orientation, with students in Cluster 2 much less mastery oriented in comparison to students in Clusters 1 or $3, F(2,36)=3.59, p<.04$.

Cluster membership was strongly associated with group membership as shown in Table $5, \chi^{2}(2, N=39)=$ $15,67, p<.0004$. There were no students without LD in Cluster 3. In contrast, most of the students without LD were in Cluster 1 . Out of the $15 \mathrm{stu}$ - dents in Cluster 1, $12(80 \%)$ of them were nondisabled. Cluster 2 had almost equal numbers of students with $\operatorname{LD}(6,43 \%$ of the 14 total $)$ and without $\operatorname{LD}(8,57 \%)$. This distribution suggests that Cluster 3 students were most similar to students with LD as defined a priori in this sample, whereas Cluster 2 students could be either. Cluster 1 students, in contrast, were most likely to be students without LD.

Further analyses of the differences among these clusters in terms of their attributions are shown in Table 6. All the significant post hoc differences from ANOVAs were between Cluster 1 and the other two clusters. Cluster 1 students were much less likely to at- tribute their success to ability, $F(2,36)$ $=5.22, p<.01$, or task difficulty, $F(2$, $36)=4.92, p<.01$. In terms of failure situations, Cluster 1 students were much less likely to attribute failure to bad luck, $F(2,36)=3.22, p<.05$, or not getting help, $F(2,36)=5.43, p<$ .009. In terms of the global attributional measures, Cluster 1 students were much more likely to attribute their success to factors under their control, $F(2$, $36)=8.73, p<.0008$. In addition, although the conservative post hoc tests did not show any differences among the three means, the overall test for significance for attributing success to internal causes was significant at the .06 level, $F(2,36)=3.21, p<.05$, 
with students in Cluster 1 more likely than other students to attribute their success to internal causes.

\section{Discussion}

The first research question concerned the differences in motivation and cognition by group membership. In support of our hypotheses and of previous research (Paris \& Oka, 1986a), we found that students with LD did show lower levels of metacognitive awareness of reading strategies in comparison to students without LD. However, we did not find that students with LD had less-positive motivational beliefs than students without LD. They had similar levels of self-efficacy, intrinsic orientation, and anxiety. That is, they reported feeling as able to accomplish reading tasks, and that they were approaching reading tasks with as much of a focus on mastery and learning, as students without $L D$. In addition, the students with LD did have a somewhat positive attributional style. They were more likely than nondisabled students to attribute their success at reading tasks to ability and their failures to bad luck and not getting assistance. They did not show any evidence of the learnedhelplessness style of attributing failure to internal, uncontrollable factors, such as ability. However, the students with LD were more likely to attribute both success and failure overall to external causes. This is a positive pattern in terms of failure, but not positive in terms of success.

The sample is small in this study, so generalizations are limited, but the picture that emerges is that the students with LD do show some gaps in their metacognitive knowledge, but their motivational beliefs are not always negative (cf. Borkowski et al., 1989). In this case, the students with LD reported feeling rather efficacious at reading, liking to read, and feeling generally focused on mastery concerns when reading. Rather than evidencing learned helplessness, our students with LD were just more external in terms of their attributions for success and failure. These results may not be surprising, given the context of instruction the students with LD receive in the resource room. They are given easier and more-manageable reading tasks and receive a great deal of help and attention from the special education teacher. These contextual factors may "buffer" any potential negative motivational effects for students who do have reading comprehension difficulties and lead them to make more external attributions to task and help factors, but clearly more research is needed before this hypothesis can be confirmed.

In terms of the relations among motivation, metacognition, and comprehension, the results show that motivational beliefs are linked to students' metacognitive awareness and comprehension. Students who had more metacognitive knowledge about reading strategies were more anxious, but they also were less intrinsically motivated and less efficacious. The latter results are somewhat surprising, given the previous research on the positive relations between the motivational beliefs of mastery goal orientation and self-efficacy and students' use of cog- nitive and self-regulation strategies (Graham \& Golen, 1991; Pintrich \& De Groot, 1990; Pintrich \& Schrauben, 1992; Schunk, 1989). The previous studies examined active cognitive engagement and use of executive control strategies, as opposed to using a metacognitive knowledge measure about reading strategies. Intrinsic goal orientation and self-efficacy may have their positive effects only on these more dynamic aspects of metacognition and self-regulation, not on more static measures of metacognitive knowledge. In terms of comprehension, students who did better on the two performance tasks were more likely to have more metacognitive knowledge and lower levels of anxiety, as would be expected. Students' attributional beliefs also were positively related to the other measures of motivation, metacognition, and comprehension, as predicted. It appears that students who attribute their success to internal causes tend to have morepositive motivational beliefs (less anxiety, more of a mastery focus, and higher self-efficacy), more metacognitive knowledge, and better comprehension scores than other students.

The third research question concerned the intraindividual patterns of
TABLE 5

Cluster Membership and Mean Differences in Motivation, Metacognition, and Comprehension Variables

\begin{tabular}{lcccc}
\hline Variable & $\begin{array}{c}\text { Cluster } 1 \\
(\boldsymbol{n}=15)\end{array}$ & $\begin{array}{c}\text { Cluster 2 } \\
(\boldsymbol{n}=14)\end{array}$ & $\begin{array}{c}\text { Cluster 3 } \\
(\boldsymbol{n}=10)\end{array}$ & $\boldsymbol{p}$ \\
\hline Anxiety & 2.70 & 3.32 & 4.15 & $<.18$ \\
Intrinsic orientation & $5.27 \mathrm{a}$ & $4.28_{\mathrm{b}}$ & $5.83_{\mathrm{a}}$ & $<.04$ \\
Self-efficacy & 5.20 & 4.71 & 5.53 & $<.32$ \\
Metacognition & $32.47_{\mathrm{a}}$ & $28.57_{\mathrm{b}}$ & $21.40_{\mathrm{c}}$ & $<.0001$ \\
Comprehension & $4.40_{\mathrm{a}}$ & $4.14_{\mathrm{a}, \mathrm{b}}$ & $3.00_{\mathrm{b}}$ & $<.02$ \\
Cloze comprehension & $7.73_{\mathrm{a}}$ & $5.57_{\mathrm{b}}$ & $4.30_{\mathrm{c}}$ & $<.002$ \\
Students without LD & 12 & 8 & 0 & \\
Students with LD & 3 & 6 & 10 & \\
\hline
\end{tabular}

Note. $L D=$ learning disabilities. Means with different subscripts differ significantly at $p<.05$, as determined by post hoc tests. 
motivation, metacognition, and comprehension. The results revealed three clusters of students who differed from one another, but group membership cut across the two groups of students with and without LD. Cluster 1 students were the "all around good" students. They did the best on the two performance measures, had the highest levels of metacognitive knowledge, were high in intrinsic orientation, and had a very positive attributional style. There were only 3 students with LD in this group. In contrast, Cluster 3 included only students with LD, and this group was the lowest in comprehension and metacognitive knowledge. However, this "low cognitive" group reported very high levels of mastery orientation, and their attributional style did not differ from that of students in Cluster 2. Cluster 2 students were between the other two groups on performance and metacognitive knowledge, but they were the lowest in intrinsic orientation and had the same attributional style as students in Cluster 3. This "low motivation" or nonmastery-oriented group had nearly equal numbers of students with and without LD.

These cluster results suggest a more refined way of looking for intraindividual profiles or patterns of the relations among motivation, metacognition, and performance, with implica-
TABLE 6

Mean Differences in Attributions by Cluster Membership

\begin{tabular}{|c|c|c|c|}
\hline Attribution & $\begin{array}{l}\text { Cluster } 1 \\
(n=15)\end{array}$ & $\begin{array}{c}\text { Cluster } 2 \\
(n=14)\end{array}$ & $\begin{array}{l}\text { Cluster } 3 \\
(n=10)\end{array}$ \\
\hline \multicolumn{4}{|l|}{ Success } \\
\hline Ability & $4.00_{\mathrm{a}}$ & $5.29_{\mathrm{a}, \mathrm{b}}$ & $5.80_{b}^{\star \star}$ \\
\hline Effort & 5.87 & 5.57 & 5.60 \\
\hline Task difficulty & $2.70_{a}$ & $4.36_{b}$ & $4.45_{b}^{* *}$ \\
\hline Luck & $1.53_{a}^{a}$ & $3.57_{b}$ & $3.65_{b}^{* *}$ \\
\hline Attention & 6.46 & 6.40 & 6.35 \\
\hline Assistance & 2.93 & 3.29 & 4.05 \\
\hline \multicolumn{4}{|l|}{ Failure } \\
\hline Ability & 1.77 & 1.75 & 2.50 \\
\hline Effort & 4.13 & 4.07 & 3.85 \\
\hline Task difficulty & 3.87 & 4.61 & 4.00 \\
\hline Luck & $1.67 \mathrm{a}$ & $1.93_{\mathrm{a}, \mathrm{b}}$ & $2.70_{b}^{*}$ \\
\hline Attention & 4.43 & 4.79 & 3.65 \\
\hline Assistance & $1.77_{a}$ & $3.29_{b}$ & $3.70_{b}{ }^{* *}$ \\
\hline \multicolumn{4}{|l|}{ Internality } \\
\hline Success & 9.10 & 6.11 & $5.60_{\dagger}$ \\
\hline Failure & 3.03 & .79 & -.40 \\
\hline \multicolumn{4}{|l|}{ Instability } \\
\hline Success & 10.03 & 9.25 & 9.40 \\
\hline Failure & 6.37 & 7.71 & 7.40 \\
\hline \multicolumn{4}{|l|}{ Controllability } \\
\hline Success & $6.97_{\mathrm{a}}$ & $2.11_{b}$ & $2.10_{b}^{* * *}$ \\
\hline Failure & 3.03 & 3.86 & 2.00 \\
\hline
\end{tabular}

Note. Means with different subscripts differ significantly at $p<.05$, as determined by post hoc tests. $t p<.06 .{ }^{*} p<.05 .{ }^{* *} p<.01 .{ }^{* * *} p<.001$. tions for research and intervention. First, the results suggest that the motivational and metacognitive variables may combine in unique ways within individuals to produce the same overall patterns of performance. For example, all the students with LD in this study are achieving at lower levels on standardized achievement tests than would be expected from their IQ scores. However, the cluster results suggest that some of these students with LD are doing poorly in reading because they lack metacognitive knowledge about reading strategies (Cluster 3, "low cognitive" group). In contrast, other students with LD (those in Cluster 2, "low motivation" group) do not have as large a deficit in metacognitive knowledge, but they are much lower in their intrinsic motivation for reading. Accordingly, there may be multiple intraindividual patterns of motivation and cognition, or "pathways," that can lead to the same overall achievement outcome (cf. Pintrich, 1989), but understanding the intraindividual differences in terms of groups or clusters allows for some generalizability across individuals, rather than a reliance on examining all individuals as unique. Of course, one of the limitations of the current study is the small sample, and future research will have to replicate the patterns found here.

Nevertheless, the general idea that there may be different intraindividual patterns of motivation and cognition for students with and without LD has implications for instructional interventions. Paralleling McKinney's (1989) suggestions, our findings suggest that different patterns of motivation and cognition may merit different instructional interventions, depending on the students' profiles. For example, the students with LD in Cluster 3 may benefit more from cognitive strategy instruction (e.g., Borkowski et al., 1989; Palincsar \& Brown, 1984) that stresses cognitive aspects of strategy training as well as attributional retraining aspects. In contrast, students in Cluster 2 may benefit from some at- 
tributional retraining (they had an attributional pattern similar to that of students in Cluster 3), but, more important, they seem to need instruction that will refocus their motivational orientation to a learning or mastery goal orientation and increase their interest in reading (see Ames, 1990; Maehr \& Midgley, 1991). This kind of instruction would help the students both with and without LD in Cluster 2. Given that special education teachers develop individual education plans for their students, this kind of information about the different patterns of motivation and cognition in students with LD could help teachers match their interventions to important individual differences in their students.

In summary, this type of multivariate analysis of intraindividual differences holds promise for research on the interaction of individual characteristics and educational contexts. It provides a method for conceptualizing the individual in terms of a multivariate profile that integrates both motivational and cognitive variables, thereby putting both "reason and affect" back together for a more complex but realistic picture of the individual learner. Future research could map the patterns of intraindividual differences across different contexts and situations to more fully examine the interaction between the individual and the context.

\section{ABOUT THE AUTHORS}

Paul R. Pintrich is currently an associate professor in the Combined Program in Education and Psychology at the University of Michigan in Ann Arbor. He received his PhD in education and psychology from the University of Michigan and specializes in research on student motivation and self-regulated learning. Eric $\boldsymbol{M}$. Anderman was a PhD candidate in the Combined Program in Education and Psychology at the University of Michigan when this study was completed. He is now an assistant professor in the Department of Educational and Counseling Psychology at the University of Kentucky. Cheryl Klobucar is an EdD candidate in the Department of Educational Studies at the University of Michigan. A school psychologist for the Garden City Public schools in Michigan, she has interests in the psychoeducational assessment of students with learning disabilities. Address: Paul R. Pintrich, 1302C School of Education, The University of Michigan, Ann Arbor, MI 48109.

\section{AUTHORS' NOTE}

An earlier version of this article was presented in a symposium, "Perspectives on the Integration of Motivational and Cognitive Models for Understanding 'At Risk' Students," at the American Educational Research Association convention in April 1992, in San Francisco.

\section{REFERENCES}

Aldenderfer, M., \& Blashfield, R. (1984). Cluster analysis. Beverly Hills, CA: Sage. Ames, C. (1990, April). Achievement goals and classroom structure: Developing a learning orientation. Paper presented at the annual meeting of the American Educational Research Association, Boston.

Borkowski, J., Carr, M., Rellinger, E., \& Pressley, M. (1990). Self-regulated cognition: Interdependence of metacognition, attributions, and self-esteem. In B. F. Jones \& L. Idol (Eds.), Dimensions of thinking and cognitive instruction (pp. 53-92). Hillsdale, NJ: Erlbaum.

Borkowski, J., Estrada, M., Milstead, M., \& Hale, C. (1989). General problem solving skills: Relations between metacognition and strategic processing. Learning Disability Quarterly, 12, 57-70.

Brown, A. L., Bransford, J. D., Ferrara, R. A., \& Campione, J. C. (1983). Learning, remembering, and understanding. In J. H. Flavell \& E. M. Markman (Eds.), Carmichael's manual of child psychology (Vol. 1, pp. 77-166). New York: Wiley. Butkowsky, I. S., \& Willows, D. M. (1980). Cognitive-motivational characteristics of children varying in reading ability: Evidence for learned helplessness in poor readers. Journal of Educational Psychology, 72, 408-422.

Canino, F. J. (1981). Learned-helplessness theory: Implications for research in learning disabilities. The Journal of Special Education, 15, 471-484.

Carr, M., Borkowski, J., \& Maxwell, S. (1991). Motivational components of underachievement. Developmental Psychology, 27, 108-118.

Chapman, J. W. (1988). Learning disabled children's self-concepts. Review of Educational Research, 58, 347-371.
Comprehensive tests of basic skills. (1981). New York: McGraw-Hill.

Deci, E. L., \& Chandler, C. L. (1986). The importance of motivation for the future of the LD field. Journal of Learning Disabilities, 19, 587-594.

Dweck, C., \& Leggett, E. (1988). A social cognitive approach to motivation and personality. Psychological Review, 95, 256-273.

Ellis, E. S. (1986). The role of motivation and pedagogy on the generalization of cognitive strategy training. Journal of Learning Disabilities, 19, 66-70.

Fincham, F., \& Cain, K. (1986). Learned helplessness in humans: A developmental analysis. Developmental Review, 6, 301-333.

Graham, S., \& Golen, S. (1991). Motivational influences on cognition: Task involvement, ego involvement, and depth of information processing. Journal of Educational Psychology, 83, 187-194.

Jacobs, J. E., \& Paris, S. G. (1987). Children's metacognition about reading: Issues in definition, measurement, and instruction. Educational Psychologist, 22, 255-278.

Johnston, P. H., \& Winograd, P. N. (1985). Passive failure in reading. Journal of Reading Behavior, 17, 279-301.

Kistner, J. A., Osborne, M., \& LeVerrier, L. (1988). Causal attributions of learningdisabled children: Developmental patterns and relation to academic progress. Journal of Educational Psychology, 80, 82-89.

Licht, B. G. (1983). Cognitive-motivational factors that contribute to the achievement of learning-disabled children. Journal of Learning Disabilities, 16, 483-490.

Lipson, J. Y., \& Wixson, K. K. (1986). Reading disability research: An interactionist perspective. Review of Educational Research, 56, 111-136.

Maehr, M. L., \& Midgley, C. (1991). Enhancing student motivation: A schoolwide approach. Educational Psychologist, 26, 399-427.

McKeachie, W. (1984). Does anxiety disrupt information processing or does poor information processing lead to anxiety? International Review of Applied Psychology, 33, 187-203.

McKinney, J. D. (1989). Longitudinal research on the behavioral characteristics of children with learning disabilities. Journal of Learning Disabilities, 22, 141-165.

McKinney, J. D., \& Speece, D. L. (1986). Academic consequences and longitudinal 
stability of behavioral subtypes of learning disabled children. Journal of Educational Psychology, 78, 365-372.

Palincsar, A. S., \& Brown, A. L. (1984). Reciprocal teaching of comprehensionfostering and comprehension-monitoring activities. Cognition and Instruction, 1, 117-175.

Paris, S. G., Cross, D. R., \& Lipson, M. Y. (1984). Informed strategies for learning: A program to improve children's reading awareness and comprehension. Journal of Educational Psychology, 76, 1239-1252.

Paris, S. G., \& Oka, E. R. (1986a). Children's reading strategies, metacognition, and motivation. Developmental Review, 6, 25-56.

Paris, S. G., \& Oka, E. R. (1986b). Selfregulated learning among exceptional children. Exceptional Children, 53, 103-108.

Paris, S., \& Winograd, P. (1990). How metacognition can promote academic learning and instruction. In B. F. Jones \& L. Idol (Eds.), Dimensions of thinking and cognitive instruction (pp. 15-52). Hillsdale, NJ: Erlbaum.

Pearl, R. (1982). LD children's attributions for success and failure: A replication with a labeled LD sample. Learning Disability Quarterly, 5, 173-176.

Pintrich, P. R. (1989). The dynamic interplay of student motivation and cognition in the college classroom. In M. Maehr \& C. Ames (Eds.), Advances in motivation and achievement: Motivation enhancing environments (pp. 117-160). Greenwich, CT: JAI Press.

Pintrich, P. R., \& De Groot, E. (1990). Motivational and self-regulated learning components of classroom academic performance. Journal of Educational Psychology, 82, 33-40.

Pintrich, P. R., \& Garcia, T. (1991). Student goal orientation and self-regulation in the college classroom. In M. Maehr \& C. Ames (Eds.), Advances in motivation and achievement: Goals and self-regulatory processes (Vol. 7, pp. 371-402). Greenwich, CT: JAI.

Pintrich, P. R., \& Schrauben, B. (1992). Students' motivational beliefs and their cognitive engagement in academic tasks. In D. Schunk \& J. Meece (Eds.), Student perceptions: Causes and consequences. Hillsdale, NJ: Erlbaum.

Pintrich, P. R., Smith, D., Garcia, T., \& McKeachie, W. (1993). Reliability and predictive validity of the Motivated Strategies for Learning Questionnaire (MSLQ). Educational and Psychological Measurement, 53, 801-813.

Scarr, S. (1992). Developmental theories for the 1990s: Development and individual differences. Child Development, 63, 1-19.

Schneider, W., \& Pressley, M. (1989). Memory development between 2 and 20. New York: Springer-Verlag.
Schunk, D. (1989). Social cognitive theory and self-regulated learning. In B. Zimmerman \& D. Schunk (Eds.), Selfregulated learning and academic achievement (pp. 83-110). New York: Springer-Verlag.

Tobias, S. (1985). Test anxiety: Interference, defective skills, and cognitive capacity. Educational Psychologist, 20, 135-142.

Tollefson, N., Tracy, D. B., Hounsen, E. P., Buenning, M., Farmer, A., \& Barke, C. R. (1982). Attribution patterns of learning disabled adolescents. Learning Disability Quarterly, 5, 14-20.

Torgesen, J. K. (1982). The learning disabled child as an inactive learner. Topics in Learning $\mathcal{E}$ Learning Disabilities, 2, 45-52.

Wechsler, D. (1974). Wechsler intelligence scale for children-Revised. San Antonio, TX: Psychological Corp.

Weiner, B. (1986). An attributional theory of motivation and emotion. New York: Springer-Verlag.

Wong, B. Y. L. (1986). How do the results of metacognitive research impact on the learning disabled individual? Learning Disability Quarterly, 10, 189-195.

Wong, B. Y. L. (1987). Metacognition and special education: A review of a view. The Journal of Special Education, 20, 9-29.

Woodcock, R. W., \& Johnson, M. B. (1977). Woodcock-Johnson psycho-educational battery. Hingham, MA: Teaching Resources Corp. 